\title{
Sustainable News and Their Impact on Company's Market Capitalization Does Sustainable News About a Company Have a Positive Relationship with Its Stock Price?
}

\author{
Moritz Plog ( $\nabla$ moritzplog@gmail.com ) \\ Hochschule Reutlingen https://orcid.org/0000-0002-9064-7160 \\ Samer Ajour El Zein \\ EAE Business School
}

\section{Research Article}

Keywords: Sustainability, DAX30, Twitter, Stock Market, Sentiment Analysis, Vector Autoregression, Granger Causality, Python

Posted Date: January 20th, 2022

DOI: https://doi.org/10.21203/rs.3.rs-1216445/v1

License: (c) (i) This work is licensed under a Creative Commons Attribution 4.0 International License.

Read Full License 


\title{
Sustainable News and their Impact on Company's Market Capitalization
}

\section{Does Sustainable News About a Company Have a Positive Relationship} with its Stock Price?

\author{
Moritz Plog', Samer Ajour El Zein ${ }^{2}$ \\ ${ }^{1}$ ESB Business School, moritzplog@gmail.com, Altenburgstraße 150, 72762 Reutlingen, Germany \\ ${ }^{2}$ Economics and Finance Department, EAE Business School, sajour@eae.es, Calle d'Aragó, 55, \\ 08015 Barcelona, Spain
}

\begin{abstract}
Abstarct
Background: As a transformation that is impacting not only nature but the international economy, climate change is here to stay. The demand for sustainable products has never been higher, a circumstance that should have an impact on the financial performance of a company. This paper aims to investigate whether sustainable news of a company has a positive impact on their stock price, by analyzing the Twitter tweets of the DAX30 members.
\end{abstract}

Results: The methodology used in this study includes the collection of Twitter tweets and financial information from the DAX30 members, followed by the execution of a sentiment analysis and Vector Autoregression (VAR) analysis based on Python programming lanuage. The opitmal lag-length of the VAR analysis has been determinded at 18 based on the Akaike, Schwarz-Bayesian and Hannan-Quinn test. Within the predermined lag-length the VAR showed significant correlations between financial performance and twitter communication in $Y_{t-1}, Y_{t-3}$ and $Y_{t-18}$. The correlation coeffiecient for the significant correlations ranged from -0.777 to 0.320 , proving that Twitter tweets containing sustainable sentiment have an impact on stock price performance of a company.

Conclusion: The results of the VAR analysis support the eligbility to use Twitter tweets as a benchmark for the impact of sustainability on the stock price performance of a company, as well as prooves that sustainable news can have a postive impact of a company's market capitalization relative to its quality. Therwith, the findings of this study raise awareness of the importance of sustainability as well as show 
the need for a transofrmation towards a sustaibale business modell in order to ensure long term value generation.

Keywords: Sustainability, DAX30, Twitter, Stock Market, Sentiment Analysis, Vector Autoregression, Granger Causality, Python

\section{Background}

The effects of climate change have long exceeded the boundaries of nature. Consumer behaviors are changing (Bruttler, 2014), international politics are adapting (Department Statista Research, 2021) and the world's economy is undergoing a transformation of the magnitude similar to the first industrial revolution (McKinsey \& Company, 2014). Equivalently, financial markets have experienced growing interest in sustainable asset classes. In fact, according to the Global Sustainable Investment Report from 2018 investments in sustainable assets have increased by 34 percent and are still expected to increase further (Global Sustainable Investment Alliance, 2018). In that constraint, for profit estimation and general analysis, analysts constantly develop new models to track and factor in the impact of sustainability. This undertaking has proven difficult, as financial statements only hold limited expressive power for analysis, historically accepted theories like the Capital Asset Pricing Model (CAPM) or Efficient Market Hypothesis (EMH) are increasingly dissatisfactory based on their limited predictive and explanatory powers (Roßbach, 2001) and ratings like the Evironmental, Social, Governance (ESG)

Risk Rating lack in terms of standardization and comparability for suitable analysis (Gyönyörová, Stachoň, \& Stašek, 2021). Therefore, analysts, investors and managers have developed alternative ways to evaluate the effect of sustainability on a company using behavioral science, such as sentiment analysis (Roßbach, 2001) and herding mentality (Janis, 1972). With these constraints in mind the evaluation of Twitter posts has proven to be a strong tool for the analysis of conventional asset classes like the S\&P500 (Mao, Wang, Wei, \& Liu, 2011) or the NASDAQ (Zhang \& Skiena, 2010).

Current literature is addressing the effects that behavioral science, more precisely the analysis of Twitter tweets using sentiment analysis, has on stock-price movements. However, research specifically targeting the effect of Twitter posts containing sustainable content has so far received limited attention. 
The magnitude that climate change and therewith sustainability poses on the world's economy is of international importance and thus legitimizes this study. This study aims to close this research gap by exploring the relationship between Twitter tweets of the DAX30 members containing sustainable sentiment and their respective stock-price movement, after exhaustively reviewing the present literature.

In order to do so, this paper will utilize the network analysis tool Node XL Pro for the purpose of gathering the sample data set as well as performing the sentiment analysis. Furthermore, after performing the sentiment analysis on the data set, a Vector Autoregression (VAR) model, developed in Python, will be used to capture the relationship between stock-price movement and Twitter posts containing sustainable sentiment. The results suggest that Twitter tweets containing sustainable sentiment have an effect on stock-price movement.

The paper is organized as follows. In Chapter 2., a literature review is presented under five broad classifications. In Chapter 3., the paper explains how the data set is constructed, and sentiment analysis, which are the key variables incorporated in the econometric specification as well as a detailed description of the VAR analysis. In Chapter 4., the results are presented. In Chapter 5., limitations are discussed. Finally in Chapter 6., the paper exhibits the main conclusions and discusses the practical implications.

\section{Consumers Demand for Sustainability is Changing the Global Economy Permanently}

Climate change has long emerged as a national issue, affecting minorities into a worldwide crisis and in turn, threatening the well-being of mankind. It is no more a problem affecting dependents and politicians of foreign countries on the other half of the world (van der Gaas \& Begg, 2012), the recent floods in Germany have proven the point that climate change has long reached the shores of Europe (Tagesschau, 2021).

The overall awareness among German dependents has increased significantly since Gilbert Plass introduced the world to the concept of climate change (Plass, 1956). In 2007, only 67 percent of the German population was aware of the term "sustainability", five years later in 2012 awareness increased to more than 80 percent, according to a survey by the Institute for Public Opinion (Institut für 
Demoskopie Allensbach, 2013). Research shows that customers in Germany focus especially on sectors like groceries, automotive and energy. Demand for sustainable groceries has grown from 5 percent in 1985 to more than 30 percent in 2010. (Bruttler, 2014). Furthermore, the demand for electricity generation from renewables has increased by more than 6.5 times throughout the past 20 years (Breitkopf, 2020). The European automotive market is transforming towards the electric vehicle. In fact, according to a study conducted by PricewaterhouseCoopers in July 2021 the electric vehicle will surpass the 20 percent threshold of total new cars sold in 2024 (PricewaterhouseCoopers, 2021).

Moreover, companies have long understood the significance of sustainability for their daily operation (Bateh, Heaton, Arbogast, \& Broadbent, 2013). The high demand for sustainably produced goods and services, the potential for premiums on profit margins, the possibility to reduce unsystematic risk through internal product diversification and political subventions have put sustainability at the top of many CEOs agendas (McKinsey \& Company, 2014). A McKinsey press release underlines the need for transforming general operations, by describing sustainability as the new must-have (McKinsey \& Company, 2019). However, according to the strategy consultancy, most companies still have a long way to go in order to fully meet costumers' demands with a completely functional as well as affordable business model (McKinsey \& Company, 2014).

The average consumer does not only inflict pressure on companies, but on the general political landscape as well. This pressure leads to political parties making climate change and sustainability their primary objective. In Germany, for instance, the party members of "Der Grünen” (The Green) have doubled since 2002 (Department Statista Research, 2021). Worldwide politics are turning more ecofriendly, putting even more pressure on the world's economy (Hite \& Seitz, 2021). Negative contribution to climate change has proven to be a liability according to the latest landmark ruling of the Court of Justice in The Hague, legally obligating Royal Dutch Shell, one of the world's largest oil conglomerates to decrease their carbon dioxide emission (Kenne \& Heede, 2021). The court ruling against Royal Dutch Shell did not only stand as an example but will pave the way for many future court rules of similar sorts. This is evidence by the fact that, Greenpeace and Die Deutsche Umwelthilfe announced on September 3, 2021, only four months after the Dutch jurisdiction, that they were planning 
to sue BMW, Daimler, Volkswagen and Wintershall Dea for non-sustainable malpractice (Agence

France-Presse $\mathrm{GmbH}, 2021$ ). The pressure exerted on companies to pursue sustainability as their main priority is increasing every day from every direction (Hossain, 2021).

\section{Importance of Sustainability on Investment Decision}

The underlying literature illustrates that, not only has customer behavior changed, but the overall preference of investors continuously drifts towards sustainably operating companies (Global Sustainable Investment Alliance, 2018). In fact, Mr. Larry Fink, chairman and chief executive officer of BlackRock was quoted saying "climate change has become a defining factor in companies' long-term prospects. I believe we are on the edge of a fundamental reshaping of finance." (Fink, 2020). In the last two decades, the financial market has experienced a veritable flood of new indices tracking the return of sustainable companies, creating a completely new investment criteria (Bianchi \& Drew, 2021).

Political pressure as well as the possible implementation of stronger sanctions increases the overall risk of investments in conventional companies (Barber, Morse, \& Yasuda, 2021). Sustainability sanctions against car manufacturers (Rode, 2018), fossil fuel conglomerates (Kenne \& Heede, 2021) or energy providers (Kolloch \& Golker, 2016) emerged onto almost every political agenda, decreasing profitability and security for investments in non-sustainable assetr classes.

Furthermore, multiple studies have demonstrated the empirical gain of sustainable investments (Bianchi \& Drew, 2021). Research shows that there is a connection between sustainability recognition and stock performance. A study from 2021, "Sustainability efforts, index recognition, and stock performance" showed that stocks exhibit abnormal returns of 3.64 percent to 4.85 percent after being listed in a sustainable index against the value weighted benchmark over a period ranging from 12 to 30 months, while the same stocks did not generate any excess returns prior to such listing (Moonsoo, Viswanathan, White, \& Zychowicz, 2021). When comparing ETFs featuring sustainable companies with conventional indices such as the S\&P500, the DAX30 or the NIKKEI 225, it underlines the idea that the annual performance of a sustainable ETFs is superior to the performance of conventional indices (Rapaport, 2020). 

stable cumulative average growth rates (CAGR) of 6 percent from 2014 to 2018, emerging with a volume of 12,306 billion euro in 2018 , making it the biggest market for sustainable investments worldwide. 48.8 percent of Europe's total invested capital was invested in sustainable asset classes demonstrating the importance of sustainability on the buyers and sellers side (Global Sustainable Investment Alliance, 2018).

ESG Risk Rating - Sustainability Indicator as a Tool for Analyst to Determine Excess Returns?

The determination of the fair value of a company's shares is normally based on the expected future value of its tangible assets (Fernandez, 2004), and as a result, the stock market is mainly an indication of the current and future financial performance of a company (Wajid, Ara, Madiha, Waseem Khan Qaiser, \& Shabeer, 2013). Nevertheless, success or failure are not exclusively based on the performance of tangible assets but are almost always an interplay of intangible and tangible assets. This is an impact that needs to be evaluated. In contrast to the determination of the value of tangible assets, which are normally based on numerical quantification, intangible assets are subject to individual perception. Therefore, the willingness to pay for given intangible asset classes often differs between investors. Moreover, analysts are continuously developing tools to estimate the impact of intangible assets on companies' financial performance (Contractor, 2001). The impact of sustainability on companies' financial performance has especially met investors' interests (Global Sustainable Investment Alliance, 2018).

One widely utilized approach, is the ESG Risk Rating, which was invented to provide a holistic assessment of qualitative and quantitative data sets of a given company in order to evaluate a company's sustainability degree (Gyönyörová, Stachoň, \& Stašek, 2021).

A McKinsey study from 2020 indicates that investors are willing to accept price premiums of about 10 percent if investments are considered sustainable, ergo carrying a low ESG Risk Rating (McKinsey \& Company, 2020), even though literature does not exclusively support the claim that low ESG Risk Ratings result in excess performance (La Torre, Mango, Cafaro, \& Leo, 2020). 

stock returns. The overall results vary by region, market, size of the company, and results are affected by economic events such as the oil crash from 2014-2015 (Investment Insights Center BNP Paribas, 2019). La Torre et al. investigated the effect of ESG Risk Ratings on members of the Eurostoxx50,

162 proving a limited correlation for a handful of companies in selected markets, such as in the energy and utilities markets (La Torre, Mango, Cafaro, \& Leo, 2020). Sahut and Pasquinii-Descomps supports La Torres et al. findings in their study on ESG Risk Ratings and firm's market performance for Switzerland, the UK, and the US, proving the correlation degree of the two variables in question strongly depends on the year and sector (Sahut \& Pasquini-Descomps, 2015). On the contrary Deng and Cheng prove a positive correlation between excess performance and ESG Risk Rating in their empirical study on the relationship between ESG indices and enterprise stock market performance for the Chinese market. Furthermore, in line with previously evaluated literature Chengs and Dengs findings demonstrate differences on the degree of influence based on the industry sector (Deng \& Cheng, 2019). Additionally, Yoon et al. demonstrates a positive correlation between ESG Risk Ratings and excess performance in the Korean market as well as illustrates once more a differentiation in significance based on the market and nature of the company.

A point of contention often raised is the lack of standardization and comparability among the various ESG Risk Rating providers (Clements, 2021; Gyönyörová, Stachoň, \& Stašek, 2021). ESG Risk Rating assessments vary significantly among rating agencies (Clements, 2021). MSCI, Bloomberg, Moody's and S\&P (Clements, 2021) just to name a few of the more than 125 rating agencies established worldwide in 2019 (Kesterton, 2019), value the degree of sustainability of an asset class all based on their own criteria. The greatest disparities among the various ESG Risk Ratings materialize in less oblique measurable criteria such as company complexity, degree of transparency or industry specifics (Gyönyörová, Stachoň, \& Stašek, 2021).

Based on the contrary outcomes of the analyzed literature as well as the lack of comparability among the various ESG Risk Ratings, it may be necessary to develop an alternative way for analysts, investors 
and managers to evaluate the influence of sustainability recognition on access financial performance of any individual enterprise on a quantitative basis.

\section{Influence of Social Media on Stock Market - Twitter as an Empirical Example}

The influence of social media on people's lives has become indispensable. Facebook, Twitter, LinkedIn, and YouTube have grown from domestic start-ups into multinational conglomerates, with no end in sight to their growth story (Perrin, 2015). Approximately two billion humans interact with Facebook on a daily basis (Scott Morton \& Dinielli, 2020). Twitter, with its 320 million monthly users, is also in no way inferior (Akram \& Kumar, 2017). The influence of social media on social interaction (Chukwuere \& Chukwuere, 2017), health (Lau, Gabarron, Fernandez-Luque, \& Armayones, 2012) and education (Selwyn \& Stirling, 2015) has long been analyzed and proven by various medicalogists, psychologists and sociologists. Moreover, the added value social media provides for companies across any maturity stage and market can no longer be denied. Social media has reshaped many companies' daily operations, changing marketing, customer engagement and news dissemination permanently (Akram \& Kumar, 2017). Deriving from this, it can be assumed that the general performance of a company is influenced by social media, reciprocating in a correlation with the stock price movement of a company. The available literature demonstrates that social media can be used as an indicator for shortterm stock market fluctuations. Furthermore, the literature points out with relative clarity that Twitter can be utilized as a stock market indicator (Porshnev, Redkin, \& Shevchenko, 2013) but leaves room for interpretation related to the effect of sustainable news published by companies and the respective influence on stock market performance.

Capital market theories like the Efficient Market Hypothesis (Moa, Counts, \& Bollen, 2011) or the Capital Asset Pricing Model have been widely accepted throughout past decades. Despite this, the consensus among scientists that historically dominant models like CAPM and EMH are increasingly unsatisfactory because of their low explanatory and predictive powers is growing. Alternative research approaches, which focus on behavioral science, promise more realistic results (Roßbach, 2001). The current literature covers the impact of sentiment analysis (Rao \& Srivastava, 2014), herding mentality 
(Janis, 1972) as well as using Twitter in order to estimate future stock price fluctuations (Bollen, Mao, \& Zeng, 2011).

Literature shows that the daily closing price as well as short-term volatility of the S\&P500 is significantly correlated with the number of daily Twitter posts mentioning S\&P500 stocks. In fact, Mao et al. proved in a study conducted in 2011 that eight out of the ten GICS (Global Industry Classification Standards) industry sectors trade volumes directly correlate with the number of daily Twitter tweets (Mao, Wang, Wei, \& Liu, 2011). In an earlier study from 2010, Mao and Zeng estimated, by using collective mood states of Twitter posts and their correlation to the value of the Dow Jones Industrial Average (DJIA), that using Twitter posts increases the tracking accuracy of the DJIAs daily movements by 86.7 percent, as well as reduces the Mean Average Percentage Error (MAPE) by more than 6 percent (Bollen, Mao, \& Zeng, 2011). Similar work focused on the NASDAQ-100 proved comparable results (Zhang \& Skiena, 2010). Furthermore, a more recent study, on the ability of sentiment containing statistically significant ex-ante information on the future movements of the S\&P500 has identified Twitter sentiments with the ability to provide lead-time information (Zheludev, Smith, \& Aste, 2014).

Sentiment analysis of Twitter posts does not solely provide analysts with greater accuracy (Bollen, Mao, \& Zeng, 2011), but is also considered superior in the realization of returns compared to historical analysis. In fact, a study carried out in 2015 showed a financial model based on social media sentiments to be 2.07 percent superior in terms of performance than a model solely based on historical analysis (Nguyen \& Shirai, 2015). Further research from 2014 comparing the performance of a bag-of-words model and a sentiment model, in the constraints of the Honk Kong stock exchange, showed that the sentiment model clearly outperformed its counterpart (Li, Xie, Chen, Wang, \& Deng, 2014). The ability to improve accuracy and enhance overall financial performance through sentiment analysis and Twitter trends should move investors and managers to incorporate such in their investment and strategic decision-making process on a general basis (Wang, Tsai, Liu, \& Chang, 2013), in order to mitigate risk and foster value.

\section{Sentiment Analysis}


Sentiment analysis is considered to be "the mining of opinions of individuals, their appraisals, and

feelings in the direction of certain objects, facts and their attributes" (Pawar, Jawale, \& Kyatanavar, 2016). Recent technological discoveries, such as deep learning techniques have solved multiple historic challenges, paving the way for technology in sectors such as marketing, health care, or politics. Moreover to that literature claims that sentiment analysis has become a key technology in the exploitation of social media data (Iglesias \& Moreno, 2019) and is also indispensable for the analysis of short-term stock market movements (Shapiro, Sudhof, \& Wilson, 2020).

Enabling analysts to utilize social media content for their investment decisions offers a significant advantage to the traditional process of predicting stock performance (Bollen, Mao, \& Zeng, 2011). Historically, analysts would invest in the stock market based on their intuition, making short-term investments highly risky and, consequently, almost impossible. Additionally, statistics, technical and fundamental analysis, as well as linear regression models, have failed to deliver constantly correct predictions (Agrawal, Chourasia, \& Mittra, 2013), therefore leading to many institutions automating their trading by using machine learning (Kahre, Darekar, Gupta, \& Attar, 2017), such as sentiment analysis (Shapiro, Sudhof, \& Wilson, 2020), in order to mitigate risks and increase performance.

Based on its versatility, a wide range of sentiment analysis approaches have been established in previous years (Devika \& Amal Ganesh, 2016). In regard to evaluating stock-price movements on the basis of Twitter posts, the literature has mainly focused on clustering posts with positive and negative connotation, such as using terms like "bullish" and "bearish" to determine the state of emotion on the respective posts (Moa, Counts, \& Bollen, 2011). Further literature simply uses tools like OpinionFinder to measure positive and negative moods (Bollen, Mao, \& Zeng, 2011). More sophisticated research evaluated moods in terms of various dimensions like calm, alert, sure, vital, kind or happy (Bollen, Mao, \& Zeng, 2011). Agarwal et al. use emotion dictionaries to label the respective emotions in terms of positivity and negativity (Agarwal, Xie, Vovsha, Rambow, \& Passonneau, 2011). Thus, it is genuinely believed that negative moods have a far greater influence on short-term stock market movements than positive ones (He, Guo, Shen, \& Akula, 2016). Additionally, research from 2011 proves a negative 
correlation between emotional tweet percentage and stock price movements. In layman's terms, if the number of emotional tweets increase, stock prices fall (Zhang, Fuehres, \& Gloor, 2011).

Even though sentiment analysis is a relatively new approach for the prediction of stock market movements (Iglesias \& Moreno, 2019), it combines significant advantages over historical models in evaluating stock-price movements (Bollen, Mao, \& Zeng, 2011). This allows analysts to precisely estimate the general mood of the market by observing the emotions and attitudes of professionals and non-professionals, reducing bias (Gonzalez-Bailon, Wang, Rivero, Borge-Holthoefer, \& Moreno, 2012). This is especially useful for topics that do not materialize on balance sheet, such as sustainability (Gyönyörová, Stachoň, \& Stašek, 2021).

\section{Research Gap}

While the existing literature proposes extensive research on the relationship between Twitter and stock-price movements, a gap remains in the literature which discusses the specific relationship between sustainable company specific news and the financial performance of the respective publicly listed company in the German market.

The results presented by the literature indicate a strong correlation of Twitter "moods" and general stock market performance. Moreover, the literature shows a noteworthy increase in demand for sustainability, with very few constructive methods to evaluate the relationship of the degree of sustainability on the financial performance of a company. This paper will build off the historical research on this topic in order to explain the relationship of sustainable Twitter posts and stock-price movements of one's enterprise.

\section{Materials and Methods}

The methodology used in this paper is explanatory and will use an inductive method in order to test a new hypothesis. The study will focus on Twitter tweets of the DAX30 members containing sustainable sentiments and the number of retweets. These variables will be compared to the stock market behaviour of the DAX30 index between the years of 2012 and 2021. Hence, the research question and hypothesis read: 
$H_{0}$ : Sustainable news about company has no positive relationship with its stock price.

$H_{1}$ : Sustainable news about a company has a positive relationship with its stock price.

\section{Data and Variable Description}

According to the literature, the stock market behaviour has been determined to be the dependent variable in this study. The DAX30 index was chosen, as it represents approximately 80 percent of the market capitalisation of all publicly listed corporations in Germany (Deutsche Börse AG, 2021). Similar movements in other markets, including the S\&P500 index or subdivisions such as the NASDAQ index and the MDAX, are expected.

In order to study the behaviour of the DAX30, the daily index adjusted close values between the years 2012 and 2021 were extracted and observed from Factset. In total, 2,437 trading days, meaning days on which the market was open and active, were selected for the purpose of the study. There are, on average, 252 trading days per year (Mayo, 2020).

The independent variables are comprised of the sentiments of the Dax30 members Twitter tweets, their retweets and they overall number of Dax30 members tweeted per day.

One aspect of the data collected includes the text of the tweets. The Twitter tweets of the respective DAX30 member have been gathered, as well as the sentiment analysis, has been carried out using the network analysis tool Node XL Pro. Node XL Pro is a tool specifically designed to acquire Twitter data and explore, analyse and visualize network data. The higher character limit considered supports the classification of the tweets, and therefore limits problems with ambiguity in sentiment analysis when decoding the selected tweets.

It is thus necessary to quantify the sentiment results of the tweets in order to use it for the regression analysis. The network analysis tool was utilized in order to carry out the quantification. As previously discussed in the literature review, sentiment analysis has been determined to be one of the most effective instruments for Twitter analysis and, therefore, has been used as the foundation of the study (Prabowo 
$\&$ Summers, 1984). From there, the Twitter posts considered have been analysed based on a previously determined set of words, which were then assigned with a value between 0 and 1,0 equalling no sustainable sentiment and 1 full equalling sustainable sentiment.

It must be considered that all sentiment classifications may not be accurate, as many users such as Adidas, Daimler and VW often used emojis in their tweets, making it more difficult to identify due to the fact that machine learning still has a way to go in the identification of semantics in language. Moreover, that Node XL Pro did not allow the data set to include hashtags.

The second independent variable observed was the number of retweets received on each tweet. Retweets represent the amount of exposure an individual tweet has, meaning the more retweets, the higher the circulation rate. When a tweet receives a large number of retweets, a higher number of people would see the respective tweet expanding its influence on users on the platform (Pancer \& Poole, 2016) and, therefore, could also achieve higher exposure to stock market participants. The number of retweets ranges between 0 and 5,801 for the observed period of over 10 years.

The third independent variable considered was the average number of DAX30 members tweeted per trading day. The average number of members tweeted per trading day represents the overall twitter activity of the DAX30. The number of members who tweeted per trading day ranges between 2 and 29 .

\section{Data Selection}

For the research purpose, it was determined to use all members of the German industry index DAX30. From these 30 companies, it was possible to extract approximately 83,000 tweets over a period of almost 10 years by using the network and machine learning tool Node XL Pro. From the number of followers and amount of activity, it can be derived that these accounts are able to encompass a large number of the Twitter universe. In order to establish a reliable regression, the dataset has been adjusted originally downloaded approximately 83,000 tweets have been considered in the constraints of the regression. 
Selected Twitter Accounts:

\begin{tabular}{|c|c|c|c|}
\hline Name & $\begin{array}{c}\text { Number of } \\
\text { Followers (2021) }\end{array}$ & Tweets Analysed & $\begin{array}{c}\text { Average Retweet } \\
\text { per Tweet }\end{array}$ \\
\hline Adidas & $4,000,000$ & 3,001 & 53.05 \\
\hline Allianz & 46,000 & 2,912 & 23.84 \\
\hline BASF & 83,300 & 2,754 & 9.50 \\
\hline Bayer & 181,000 & 2,617 & 6.81 \\
\hline BMW & $2,200,000$ & 2,338 & 8.85 \\
\hline Continental & $\mathrm{n} / \mathrm{a}$ & $\mathrm{n} / \mathrm{a}$ & $\mathrm{n} / \mathrm{a}$ \\
\hline Covestro & 28,600 & 2,623 & 9.16 \\
\hline Daimler & $3,700,000$ & 3,200 & 9.90 \\
\hline Delivery Hero & 6,100 & 859 & 3.10 \\
\hline Deutsche Wohnen & 4,496 & 1,135 & 0.75 \\
\hline Deutsche Bank & 672,200 & 1,307 & 5.89 \\
\hline Deutsche Börse & 22,900 & 3,011 & 2.22 \\
\hline Deutsche Post & 43,200 & 2,245 & 21.77 \\
\hline Deutsche Telekom & 80,400 & 3,200 & 2.40 \\
\hline E.ON & 38,300 & 2,907 & 22.69 \\
\hline Fresenius Medical Care & 5,111 & 540 & 2.84 \\
\hline Fresenius & 14,800 & 2,867 & 9.01 \\
\hline Heidelberg Cement & 1,491 & 278 & 1.37 \\
\hline Henkel & 21,300 & 2,625 & 2.99 \\
\hline Infineon & 13,400 & 2,971 & 9.11 \\
\hline Linde & 14,700 & 3,077 & 4.15 \\
\hline Merck Group & 22,300 & 2,375 & 3.89 \\
\hline MTU Aero Engines & 1,176 & 155 & 4.85 \\
\hline Münchener Rück & 64,800 & 2,937 & 9.13 \\
\hline RWE & 19,100 & 2,652 & 2.99 \\
\hline SAP & 290,200 & 1,530 & 9.86 \\
\hline Siemens & 201,200 & 1,998 & 25.03 \\
\hline Siemens Energy & 179,100 & 2,806 & 20.10 \\
\hline Vonovia SE & 3,612 & 2,315 & 1.97 \\
\hline Volkswagen & 637,800 & 1,746 & 6.79 \\
\hline Total & $12,596,586$ & 63,604 & 10.17 \\
\hline
\end{tabular}




\section{Data Extraction}

Twitter is fed with a constant stream of new information every second of every day. With an estimated 500 million tweets posted per day, transforming into 6,000 tweets issued per second (Twitter Usage Statistics, 2021). Due to the sheer number of tweets being posted every day, it is challenging to observe them in an accurate and efficient way without the use of technology and software in combination with Microsoft Excel or other analytics tools (Laitenberger \& Dreyer, 1998).

Based on the intuitive interface, the possibility to filter for Twitter posts per user, as well as the ability to perform the sentiment analysis with the same application, the machine learning and data analysis tool Node XL Pro was chosen.

In order to ensure comparability among the 30 DAX30 members it was decided to focus on the number of Twitter posts issued rather than a time duration. Under this constraint, it was determined to consider up to the 3,200 most recent Twitter tweets of each respective member. Generally, it must be said that the degree of engagement varies between the respective DAX30 members, leading to certain discrepancies in the number of posts issued. Therefore, it was not possible to acquire a sample dataset of 3,200 tweets of every member.

All the data collected is from primary sources, extracted from the tweets themselves and were posted from users during the specified time period. There was no use of outside data from sources other than Twitter to influence the results of the data.

Furthermore, to adjust for the influence of the COVID-19 pandemic, the tweets for the year 2020 were excluded from the study.

The data collected included 29 out of the 30 companies mentioned above (except for Continental, as no data was available), the date of their tweets, the number of likes, the number of retweets, the hashtags used, the wording of the tweet itself, as well as the sentiment behind the tweet.

Following the data extraction, it was necessary to reorganize and adjust the data set. The DAX30 index return in percentage per day between the years of 2012 and 2021 (Factset, 2021), has been matched with the respective tweets of the DAX30. In order to derive a standardized sentiment per trading day of 
all DAX30 members, the respective sentiment per individual tweets have been accumulated on a per day basis and then divided by the number of tweets. The same producer has been used for the retweets and number of Dax30 members tweeted per trading day. In a second step the daily averages have been transformed into monthly averages. Based on the available literature, as well as based on the nature of the stock market, a monthly average view of the values was decided to be supirior for the statistical analysis (Morse, 1984).

Tweets that fell on weekends or holidays, ergo non-trading days, have not been considered. Based on Twitter's short-term nature, tweets older than one day pose a limited influence on the observed index. Therefore, only the tweets posted on the 2,437 trading days between 2012 and 2021 are considered as data input for the regression analysis.

Excluding non-trading days and all trading days of 2020, the study contains 2,183 trading days or 105 months, featuring 63,604 tweets. In total, there were 434 trading days classified with zero sentiment, 1,305 trading days containing a sentiment up to 0.5 and 444 trading days containing a sentiment greater than 0.5 , making up 19.8 percent, 59.8 percent and 20.3 percent, respectively.

\section{Statistical Model}

After cleaning the data, a statistical model needs to be applied in order to determine the trustworthiness of the results and test the proposal. For this paper, the Vector Autoregression (VAR) model has been chosen. This model was determined to be the most appropriate for the data, because it considers all necessary factors and fits the assumptions that could have influenced the interpretation of the results. In addition to that, it presents a superior alternative to the multivariate simultaneous equation models for macroeconometric analysis, based on its ability to describe the dynamic structure of variables (Hashimzade \& Thornton, 2013). The complete VAR model has been executed with Python Machine Learning.

The VAR model describes the behaviour of a vector of $k$ variables by using the lagged values of the $\mathrm{k}$ variables as the regressor. The value of a variable $\mathrm{x}$ at time $\mathrm{p}$ depends on its lagging value, as well as on all other endogenous variables of the model (Abrigo \& Love, 2016). The VAR model is generated 
through a system of equations, in which each variable has its own equation. Therefore, the system of equations of a VAR model featuring two endogenous variables reads as follows:

$$
Y_{1, t}=a_{1}+\beta_{11,1} Y_{1, t-1}+\beta_{12,1} Y_{2, t-1}+\beta_{11,2} Y_{1, t-1}+\beta_{12,2} Y_{2, t-1}+\epsilon_{1, t}
$$

$$
Y_{2, t}=a_{2}+ß_{21,1} Y_{1, t-1}+ß_{22,1} Y_{2, t-1}+ß_{21,2} Y_{1, t-1}+ß_{22,2} Y_{2, t-1}+\epsilon_{2, t}
$$

$Y_{t}=$ Vector of Time Series Variable

$\mathrm{a}=$ Vector of Intercept

$\beta_{1}=$ Vector of Coefficient

$Y_{t-1}=$ Vector of Time Series Variable in the Previous Lag

The VAR model is widely used as a statistical model to measure interrelation between two or more variables (Toda \& Phillips, 1994). In addition, it presents a way to test for shared restrictions across multiple equations. It is necessary to include the VAR model in this study, as it portrays the relationship of independent variables on the dependent variable.

1. The variables within the model influence each other (Granger Causality Test).

2. Underlying data is generated from a stationary process, whose statistical properties are independent of time (Cointegration Test).

3. There is no significant serial correlation (Durbin Watson Statistic).

4. The coefficients in the main matrix are estimated by Ordinary Least Square Regression (OLS). (Hanck, Arnold, Gerber, \& Schmelzer, 2021)

\section{Granger Causality Test}



utilised to describe another set of variables. According to the Granger Causality Test, this is the case

417

418

419

420

421

422

423

when the causality of one set of variables is compared to another set of variables is greater than zero (Toda \& Phillips, 1994). In other words, the null hypothesis can be rejected if the past values of time series considered $(\mathrm{x})$ do not cause the other series variables (y). If a set of variables ( $\mathrm{x}$ ) is found to be impactful by predicting another set of variables (y), (x) is considered Granger-cause. If (x) fails to cause (y) it is considered and labelled fail to Granger-cause (Zivot \& Wang, 2002). The null hypothesis is to be rejected if the $\mathrm{p}$-value retrevied from the test is $<0.05$.

Equation:

$$
P\left[Y(t+1) \varepsilon \mathrm{A} \mid \mathrm{I}(\mathrm{t}) \neq \mathrm{P}\left[\mathrm{Y}(\mathrm{t}+1) \varepsilon \mathrm{A} \mid I_{-x}(t)\right]\right.
$$

$\mathrm{P}=$ Probability

$\mathrm{A}=$ Arbitrary Non-Empty Set

$\mathrm{I}(\mathrm{t})$ and $\mathrm{I}_{-\mathrm{X}}(\mathrm{t})=$ All Information Available

$\mathrm{t}=$ Time

(Eichler, 2011)

\begin{tabular}{|l|r|r|r|r|}
\hline & \multicolumn{1}{|l|}{ Return_x } & TS_x & Retweet_x & MtpTD_x \\
\hline Return_y & 1.0000 & 0.0011 & 0.0000 & 0.0002 \\
\hline TS_y & 0.0000 & 1.0000 & 0.0000 & 0.0344 \\
\hline Retweet_y & 0.0000 & 0.0000 & 1.0000 & 0.0000 \\
\hline MtpTD_y & 0.0000 & 0.0774 & 0.0001 & 1.0000 \\
\hline
\end{tabular}

Table 2 Results of the Granger Causality Test

Furthermore, when considering the results of the values of the Granger Causality Test it can be stated that the null hypthesis is to be rejected for almost all sets of variables. The only causality for which the null hypothesis cannot be rejected is $T S \_x$ and MtpTD_Y.

\section{Cointegration Test}

The Cointegration Test was established in order to evaluate whether a correlation between multiple time series can be found. In other words, it is used to test if a statistically significant relationship can be 
detected between two sets of variables. In order to test for statistical significance, the Johansen Test was carried out, as it allows for more than one cointegration relationship (Johansen, 1991).

438

\begin{tabular}{|l|l|r|}
\hline Variable & Trace Statistic & Critical Value at $<\mathbf{0 . 0 5}$ \\
\hline Return & 51.15 & 40.1749 \\
\hline TS & 17.23 & 24.2761 \\
\hline Retweet & 5.24 & 12.3212 \\
\hline MtpTD & 1.39 & 4.1296 \\
\hline
\end{tabular}

Table 3 Results of the Johansen Cointegration Test

According to the Johansen Test, the null hypothesis can be rejected if the trace statistic is greater than the critical value at the significance level. Therefore, the null hypothesis can only be rejected for the variable return. Literature on the topic states that, in case of cointegration, a vector error correction model (VECM), which captures the degree of cointegration, is to be applied, whereas the VAR approach is the model to use in the case of limited cointegration (Pfaff, 2008).

\section{Stationarity Test}

As previously discussed, one of the main assumptions of the VAR model is stationarity. The VAR model assumes stationarity of the set of variables, meaning that statistical characteristics like mean and variance do not change over time. Within the constraints of the research, the Augmented Dicker Fuller (ADF) Test has been used. The ADF Test is based on the Dicker-Fuller (DF) Test. The DF Test is a unit root test, which tests whether $\alpha=1$ is the coefficient on the first lag of a set of variables $\left(Y_{(t-1)}\right)$. The ADF Test augments the DF Test equation to incorporate a high-order regressive process into the model

Equation:

$$
y_{t}=c+\beta+\alpha y_{t-1}+\Phi_{1} \Delta Y_{t-1}+\Phi_{2} \Delta Y_{t-2} \ldots \Phi_{p} \Delta Y_{p-1}+\epsilon_{t}
$$

$$
\mathrm{c}=\text { Constant }
$$

$\beta=$ Coefficient

$$
y_{t-1}=\operatorname{Lag} 1 \text { of Time Series }
$$


Furthermore, in the case of non-stationarity, the time series can be adjusted by differencing the dataset. In this particular case, it was necessary to difference the data set twice in order to ensure stationarity among the set of variables.

\section{Lag Length Selection}

Lag length describes the timespan that has been observed for the model. In order to minimize residual correlation, it is important to consider the correct lag length, VAR(p), within the constraints of the VAR model. The VAR(p) model can be determined using various approaches. The Akaike (AIC), Schwarz-Bayesian (BIC) and the Hannan-Quinn (HQ) are the widely used approaches. As the AIC is considered to generally overestimate the lag length, it has been decided to focus on the BIC and HQ approach within the constraints of this paper (Zivot \& Wang, 2002; Zivot \& Wang, 2002).

Equation:

$$
B I C(p)=\ln |\Sigma(p)|+\frac{\ln T}{T} p n^{2}
$$

$\Sigma(p)=T^{-1} \sum_{t=1}^{T} \varepsilon \mathrm{t}=$ Covariance Matrix without a Degree of Freedom Correction

$\mathrm{T}=$ Sample Size

$p n^{2}=$ Penalty Function for Large VAR(p) Model

\begin{tabular}{|l|r|r|r|}
\hline Lags & AIC & BIC & HQ \\
\hline 0 & 5.048 & 5.166 & 5.095 \\
\hline 1 & 3.331 & 3.922 & 3.568 \\
\hline 2 & 2.369 & 3.433 & 2.796 \\
\hline 3 & 2.060 & 3.597 & 2.677 \\
\hline 4 & 1.796 & 3.806 & 2.603 \\
\hline 5 & 1.798 & 4.281 & 2.795 \\
\hline 6 & 1.788 & 4.744 & 2.974 \\
\hline 7 & 1.803 & 5.232 & 3.178 \\
\hline 8 & 1.600 & 5.502 & 3.166 \\
\hline 9 & 1.621 & 5.996 & 3.376 \\
\hline 10 & 1.437 & 6.285 & 3.382 \\
\hline
\end{tabular}




\begin{tabular}{|l|r|r|r|}
\hline 11 & 1.389 & 6.710 & 3.524 \\
\hline 12 & 1.016 & 6.810 & 3.341 \\
\hline 13 & 1.085 & 7.352 & 3.600 \\
\hline 14 & 0.9738 & 7.714 & 3.678 \\
\hline 15 & 0.2292 & 7.442 & 3.123 \\
\hline 16 & -1.210 & 6.476 & 1.873 \\
\hline 17 & -3.280 & 4.879 & -0.006231 \\
\hline 18 & $-5.414^{*}$ & $3.218^{*}$ & $-1.951^{*}$ \\
\hline
\end{tabular}

Table 4 Results of the AIC, BIC \& HQ Tests

The smallest value of the respective approach identifies the lag length to be considered. The results indicate lag 18 for the AIC test, lag 18 for the BIC test and lag 18 for the HQ test, therefore lag 18 has been identified as the optimal lag length (Zivot \& Wang, 2002).

\section{Durbin Watson Test}

In order to underline the expressiveness of the model, it was necessary to carry out a Durbin Watson Test. The Durbin Watson Test was designed to detect serial correlation in the residuals from regression analysis. In other words, if a correlation remains in the model, there are certain time series patterns that have not been explained by the model so far. It is necessary to observe any time related data differences when considering time series data, for instance by measuring the return of the DAX30 on different days (Tillman, 1975).

Equation:

$$
D W=\frac{\sum_{t=2}^{T}\left(\left(e_{t}-e_{t-1}\right)^{2}\right)}{\sum_{t=1}^{T} e_{t}^{2}}
$$

$\mathrm{T}=$ Time

$\mathrm{E}=$ Residuals of the Regression

The values of the Durbin Watson Test can range between 0 and 4. Generally, it can be considered that the closer the output value ranges around 2 , the lower the serial correlation $(0=$ positive serial correlation; 4 = negative serial correlation) is. 


\begin{tabular}{|l|r|}
\hline Variable & Value \\
\hline Return & 2.46 \\
\hline TS & 1.7 \\
\hline Retweet & 1.55 \\
\hline MtpTD & 2.27 \\
\hline
\end{tabular}

The results presented from the Durbin Watson Test demonstrate that all sets of variables considered in the VAR analysis range around the benchmark of 2. Consequently, it can be deduced that the model describes the majority of the time series pattern.

After the implementation of the VAR statistical tests, the corresponding determination of significance of the data set, and the model validation, it is possible to run this statistical test and test the paper hypothesis. Chapter 4. and 5. will elaborate in detail on the findings of the study, discuss the results, as well as provide recommendations for further analysis.

\section{Results}

This research paper investigated whether sustainable news published by a given company has an impact on their respective stock market performance. The purpose of this research is to address the gap in the literature connecting sustainable news and the stock market. As previously outlined in the literature review, studies generally focused on the overall power of Twitter on the stock market and the possibility of using the Twitter data-stream for stock market predictions. The desired outcome of the research elaborated in this paper is to build on the previously conducted research linking Twitter and the financial markets, in order to show the relationship of perceived sustainability with the financial performance of a company as well as to provide an alternative investment strategy for investors.

Generally, some members of the DAX30 have a significantly higher engagement rate than others. For instance, Daimler is extremely active on Twitter, with more than 3,000 tweets analysed for the purpose of this study, resulting in an average tweet count per trading day of approximately 1.3 tweets. On the contrary, MTU Aero Engines only tweeted 155 times within the analysed time span, transforming into an average tweet count per trading day of approximately 0.06 . It is thus obvious that the observed 
accounts contain biases in the representations, as well as the type of content they express (Liu \& Zhang, 2012). An automotive company or an energy producer is typically more engaged with the topic of sustainability than a software producer.

\section{Regression Results}

This paper utilized, as explained in Chapter 3., the VAR model in order to test the null hypothesis of whether sustainable news about a company has no positive relationship with its stock price.

\section{Summary of Regression Results 1.}

\begin{tabular}{lclr}
\hline Method: & VAR & & \\
Model: & OLS & & \\
Date: & Wed, 08, Dec 2021 & & \\
Time: & $23: 43: 00$ & & 3.21758 \\
\hline No. of Equations: & 4.00000 & BIC: & -1.95105 \\
Nobs: & 72.0000 & HQ: & 0.451991 \\
Log likelihood & 51.5415 & Final Prediction Error: & 0.0345929 \\
AIC & -5.41426 & Det(Omega_mle): &
\end{tabular}

Table 6 Summary of Regression Results 1.

The coefficients of the main variables of the matrix in the VAR model were determined by the OLS, as according to the assumptions of the VAR model (Hanck, Arnold, Gerber, \& Schmelzer, 2021). The number of equations equals four in order to include all the chosen variables. As previously discussed in reach their minimum at that specific lag.

From the results, that were acquired through the VAR analysis for the time series of interest, it can be derived that not all variables across the 18 lags considered presented p-value levels of statistical significance of $<0.05$. 
number of retweets carries an average p-value of 0.2124 and index member who tweeted per trading day carries an average p-value of 0.2422 across the observation period.

Therefore, in order to derive a statistically relevant equation from the results of the VAR model, only the regressors which carry a p-value lower than 0.05 were considered.

\begin{tabular}{|l|r|r|r|r|}
\hline \multicolumn{1}{|c|}{ Regressor } & Coefficient & Std. Error & \multicolumn{1}{c|}{ t-stat } & \multicolumn{1}{c|}{ p-value } \\
\hline L1.Return & -1.438286 & 0.319068 & -4.508 & 0.000 \\
\hline L1.TS & -0.628778 & 0.299846 & -2.097 & 0.036 \\
\hline L1.Retweet & 0.130401 & 0.042623 & 3.059 & 0.002 \\
\hline L1.MtpTD & -0.145241 & 0.067604 & -2.148 & 0.032 \\
\hline L3.TS & -0.777472 & 0.377783 & -2.058 & 0.040 \\
\hline L4.MtpTD & -0.244289 & 0.112911 & -2.164 & 0.030 \\
\hline L7.Retweet & -0.384168 & 0.173336 & -2.216 & 0.027 \\
\hline L12.Retweet & -0.421240 & 0.175459 & -2.401 & 0.016 \\
\hline L15.MtpTD & 0.468970 & 0.192277 & 2.439 & 0.015 \\
\hline L17.Retweet & -0.163211 & 0.075322 & -2.167 & 0.030 \\
\hline L18.TS & 0.320830 & 0.162396 & 1.976 & 0.048 \\
\hline L18.MtpTD & 0.528951 & 0.215633 & 2.453 & 0.014 \\
\hline
\end{tabular}

Table 7 Regression Results 2. derived:

536

$\widehat{Y}_{t}$$$
=-0.013 \alpha_{t}-1.438 x_{t-1}-0.629_{y-1}+0.130_{t-1}-0.145 m_{t-1}-0.777 y_{t-3}-0.244 m_{t-4}-0.384 z_{t-7}
$$

$$
-0.421 z_{t-12}+0.469 m_{t-15}-0.163 z_{t-17}+0.320 y_{t-18}+0.529 m_{t-18}
$$

$539 \widehat{Y}_{t}=$ Prediction of Return

$\alpha=$ Constant

$\mathrm{x}=$ Return

$\mathrm{y}=$ Twitter Tweet Containing Sustainable Sentiment 
$\mathrm{m}=$ Members Tweeted per Trading Day

$\mathrm{t}=$ time

The equation above, derived from the VAR model, includes 12 variables of the 72 original variables possible. By considering the coefficients of the individual identified significant variables, it is possible to determine their impact on $\widehat{Y}_{t}$. For instance, the variable return in lag t-1 effects $\widehat{Y}_{t}$ by -1.438 . In other words, for every additional $X_{t-1}$, there would be a negative impact of 1.438 on $\widehat{Y}_{t}$.

The variable Twitter tweets containing sustainable sentiment have been identified to be significant in lag $\mathrm{t}-1, \mathrm{t}-3$ and $\mathrm{t}-18$. Considering the results, it was possible to quantify a negative impact of $\mathrm{y}$ on $\widehat{Y}_{t}$ in $\mathrm{t}-1$ and $\mathrm{t}-3$ as well as a positive in $\mathrm{t}-18$, proving that Twitter tweets containing sustainable sentiment have an impact on stock-price performance.

According to the VAR, the variable retweets is significant in lag $\mathrm{t}-1, \mathrm{t}-12$ and $\mathrm{t}-18$. The results present a negative impact of $\mathrm{z}$ on $\widehat{Y}_{t}$ in lag $\mathrm{t}-12$ and $\mathrm{t}-18$, as well as a positive in $\mathrm{t}-1$. Consequently, it is possible to derive that retweets carry a certain relevance when evaluating stock market performance.

The same goes for the number of DAX30 members that tweeted per day. The VAR model detected a significant relationship in lag $\mathrm{t}-1, \mathrm{t}-4, \mathrm{t}-15$ and $\mathrm{t}-18$. The data presents a positive impact of $\mathrm{m}$ in lag $\mathrm{t}-$ 15 and $\mathrm{t}-18$ and a negative impact in lag $\mathrm{t}-1$ and $\mathrm{t}-4$.

The data shows that communication, in this case, manifested by retweets or the number of people tweeting among the Dax30 members, can have a negative impact on the financial performance of a company, see $m_{t-1}$ or $z_{t-12}$. However, the data also presents that it can have a positive effect on stockmarket performance, especially in the case of Dax30 members who tweeted per day, whereas the positive coefficient of the significant variables outweigh the negatives by far within the timeframe considered. In addition to this, the findings also present a positive impact of $\mathrm{y}$ and $\mathrm{m}$ on $\widehat{Y}_{t}$ in lag $\mathrm{t}-18$. Subsequently, it can be derived that not only the quantity of communication but the quality of it, and in this case sustainability related topics, may have an impact on a company's financial performance.

In conclusion it can be stated that the findings support the thesis that communication in the context of sustainability has an impact on financial performance. However, the findings show that this influence 
is not exclusively positive. Therefore, it is not possible to fully reject the null hypothesis of this paper.

571 The findings point to the conclusion that it is not exclusively the quantity of communication dealing

572 with sustainability that matters, but an interaction between its quantity and quality.

\section{Discussion}

574

575

By focusing the research on one selected index, it increased practicality in terms of data interpretation, opposed to considering every company listed on every stock market. However, the sample size should be considered. For this purpose, it must be acknowledged that considering one index in one particular country is a limitation of this study and therefore, further literature could extend this study by including a larger sample size.

The second limitation of this research is the availability, as well as the uniformity of the data considered. This study only managed to consider 29 of the 30 DAX30 members since Continental did not have an active Twitter account. There are opportunities for additional research to utilize a larger number of observations to improve statistical accuracy and therefor achieve better outcomes. Furthermore, the data gathering tool Node XL Pro did only allow to download the 3,200 most recent Twitter tweets on a per user bias and, therefore, limited the validity of some Twitter accounts. With technological advances, further research could utilize a data gathering tool enabling the download of greater amount of historic Twitter posts.

The third limitation includes the sentiment analysis. As previously mentioned, artificial intelligence has not yet matured in its capabilities to detect social nuances (Ferrara, 2016), sarcasm or any other nonverbal communication styles. In addition to that Node XL Pro, the program utilized for the sentiment analysis was not able to consider hashtags in its analysis. Nevertheless, with further research and technological progress artificial intelligence technology will mature, leading to better results.

Finally, the methodology considered in this research could contain another potential limitation. As discussed in Chapter 3., this research relied on a VAR model, as it addressed all the necessary factors, and enabled suitable comparability of the data structure. Within these constraints, it was determined to 
use monthly averages for the VAR model. Further research could generate additional value by using daily averages while building on the statistical model considered in this paper.

Moreover, that additional statistical models could have been added to the research approach in order to generate extra value, as well as to increase the quality of the findings, which would have however exceeded the constraints of this particular study, and, therefore, leaves room for further research. Models that could be considered in further research studies, alongside the VAR model, are the Structured Vector Autoregression model (SVAR), allowing to predict the effect of certain shocks like political change, changes in the economy or natural disasters (Inoue, 2013) or the Autoregressive Conditional Heteroskedasticity (ARCH) model (Engle, 1982), which can be applied to predict volatilities to further predict the variability of the variables chosen. In addition to that, with increased statistical abilities, improvements could be made to the model, which could serve for additional research purposes.

Thus, this research has started to answer the question of whether sustainable Twitter posts of a given company affect their respective stock-market performance. The results of this paper look at the explanation of the independent variables. With continuous improvements and methods to agitate the limitations in this research, further studies could be conducted to build of the findings in this paper in order to prove the importance of sustainability for companies, managers and investors.

\section{Conclusion}

The impact of climate change on nature and the economy has long been omnipresent (Robinson, 2021) and become a challenge that companies have to master. The transformation to a sustainably operating company provides, apart from various risks, opportunities for risk mitigation (Anderson, 2006), customer acquisition (Bruttler, 2014), increased profitability (Ghassim \& Bogers, 2019) and thus, offers every company, beyond the aspect of sustainability itself, the potential to increase its intrinsic value. The aim of this research is to highlight the positive impact of sustainability on a company's financial performance, based on the correlation between stock market performance and a company's communication with customers on the internet. The results of the statistical investigation show a dependency between dependent and independent variables. 
The dependency between stock-market performance and communication describes the possibility

622 for companies to generate quantitative added value through sustainability-focused communication.

623 From this, a clear guideline for the management of every company can be derived, and the importance

624 of sustainable business management is once again underlined.

625 Furthermore, the approach used in this paper to quantify the dependency of the variables described

626

627

628

629

630

631

632

633

634

635

636

637

638

639

640

641

642

643

644

enables a more precise determination of the general influence of sustainability on the financial performance of a company. This enables a more accurate assessment of the importance of sustainability for a company's operation (Rehman Khan \& Yu, 2021) which certainly varies across organisations (Walzenberg, Lonca, Hanes, Eberle, \& Carpenter, 2021), and thus can serve as a basis for long-term strategic decisions making (Partidario, 2021).

The goal of this paper was accomplished, by complementing and filling current literature gaps on this subject, as well as to raise awareness of sustainability recognition. The research outcomes raise awareness on the importance of sustainability in enterprises (Kamalduin, Xavier, \& Amin, 2021) and open a further line of research in order to provide a tool to measure the effects of sustainability on financial performance, (Nguyen, Elmagrhi, Ntim, \& Wu, 2021) as well as help increase returns while mitigating risks for investors. Ultimately, the financial and environmental areas of interest align. Time will tell whether the consensus of interest can be leveraged into creating long-term sustainable value for both financial and ecological stakeholders. 
647 ARCH: Autoregressive Conditional Heteroskedasticity; BIC: Schwarz-Bayesian; CAGR: Cumulative 648 Average Growth Rate; CAPM: Capital Asset Pricing Model; DIJA: Dow Jones Industrial Average; 649 EMH: Efficient Market Hypothesis; ESG: Environmental, Social, Governance; GICS: Global Industry 650 Classification Standards; HQ: Hannan-Quinn; MAPE: Mean Average Percentage Error; MtpTD: DAX30 Member tweeted per Tradind Day; OLS: Ordinary Least Square Regression; SVAR: Structured 652 Vector Autoregression; TS: Twitter Tweets containing sustainable Sentiment; VAR: Vector 653 Autoregression; VECM: Vector Error Correction Model

\section{Acknowledgements}

655 Not applicable

\section{Author's Contribution}

657 MP: conceptualisation, methodology, investigation, writing-original draft, writing-review and editing. 658 SAEZ: investigation, writing-review and paper management. All authors read and approved the final 659 manuscript.

660 Funding

661 Not applicable

\section{Availability of data and materials}

663 The datasets used and/or analysed during the current study are available from the corresponding author 664 on reasonable request. 


\section{Ethics approval and consent to participate}

672 Not applicable

\section{Consent of publication}

674 Not applicable

675 Animal research

676 Not applicable

677 Competing interest

678 The authors declare that they have no known competing personal interests or

679 relationships that could have appeared to infuence the scientifc work in this

680 manuscript.

681 Author details

$682{ }^{1}$ ESB Business School, Altenburgstraße 150, 72762 Reutlingen, moritz.plog@ student.reutlingen-

683 university.de

684

685

686

687

688

689

690

691 


\section{References}

1. Abrigo, M. R., \& Love, I. (2016). Estimation of panel vector autoregression in Stata. The Stata Journal, 778-804.

2. Agarwal, A., Xie, B., Vovsha, I., Rambow, O., \& Passonneau, R. (2011). Sentiment Analysis of Twitter Data. Department of Computer Science Colombia University.

3. Agence France-Presse GmbH. (2021). Umwelthilfe und Greenpeace drohen Konzernen mit Klage. Die Reinpfalz.

4. Agrawal, J., Chourasia, V., \& Mittra, A. K. (2013). State-of-the-Art in Stock Prediction Techniques. International Journal of Advanced Research in Electrical, pp. 1360-1366.

5. Akram, W., \& Kumar, R. (2017). A Study on Positive and Negative Effects of Social Media on Society. International Journal of Computer Sciences and Engineering, pp. 347-354.

6. Allison, P. (2014). Prediction vs. causation in regression analysis. Statistical Horizons.

7. Anderson, D. R. (2006). The critical importance of sustainability risk management. Risk Management, 66-72.

8. Atsalakis, G. S., \& Valavanis, K. P. (2009). Surveying stock market forecasting techniques Part II: Soft computing methods. Expert Systems and Applications, 5932-5941.

9. Barber, B. M., Morse, A., \& Yasuda, A. (2021). Impact Investing. Journal of Financial Economics, 162-185.

10. Bateh, J., Heaton, C., Arbogast, W. G., \& Broadbent, A. (2013). Defining Sustainability In The Business Setting. Journal of Sustainable Management.

11. Bianchi, R. J., \& Drew, M. E. (2021). Sustainable stock indices and long-term portfolio decisions. Jouarnal of Sustainable Finance, pp. 303-317.

12. Bollen, J., Mao, H., \& Zeng, X.-J. (2011). Twitter mood predicts the stock market. Journal of Computer Science, pp. 1-8. 
13. Breitkopf, A. (2020). Bruttostromerzeugung aus Erneuerbaren Energien in Deutschland in den Jahren 1990 bis 2020. Statista.

14. Breusch, T., \& Pagan, A. (1979). A Simple Test for Heteroscedasticity and Random Coefficient Variation. Econometria, 1287-1294.

15. Bruttler, O. (2014). Nachhaltigkeit als Kriterium. Ökologisches Wirtschaften, 41-45.

16. Chukwuere, J. E., \& Chukwuere, P. C. (2017). The impact of social media on social lifestyle: a case study of university female students.

17. Clements, R. (2021). Why Comparability is a Greater Problem Than Greenwashing in ESG. Forthcoming 13 William \& Mary Business Law Review, pp. 0-47.

18. Contractor, F. J. (2001). Valuation of Intangible Assets in Global Operations. Quorum Books.

19. Craney, T. A., \& Surles, J. G. (2007). Model-Dependent Variance Inflation Factor Cutoff Values. Quality Engineering, pp. 391-403.

20. Deng, X., \& Cheng, X. (2019). Can ESG Indices Improve the Enterprises' Stock Market Performance?—An Empirical Study from China. Sustainability.

21. Department Statista Research. (2021, November 14). www.statista.com. Retrieved from

22. Deutsche Börse AG. (2021, November 29). deutsche-boerse.com. Retrieved from https://www.deutsche-boerse.com/dbgde/unternehmen/wissen/boersenlexikon/boersenlexikon-article/DAX-242898

23. Devika, M. D., \& Amal Ganesh, C. S. (2016). Sentiment Analysis: A Comparative Study on Different Approaches. Procedia Computer Sience, pp. 44-49.

24. Eccles, R. G., \& Klimenko, S. (2019). The Investor Revolution - Shareholders are getting serious about sustainability. Havard Business Review. 
25. Eichler, M. (2011). Causal Inference in Time Series Analysis.

741 26. Engle, R. (1982). Autoregressive conditional heteroscedasticity with estimates of the variance of United Kingdom inflation. Econometrica.

27. Factset. (2021, November 12). www.factset.com. Retrieved November 12, 2021, from https://www.factset.com/

28. Farrar, E. D., \& Glauber, R. R. (1967). Multicollinearity in Regression Analysis: The Problem Revisited. The Review of Economics and Statistics, pp. 92-107.

29. Fernandez, P. (2004). Company Valuation Methods. The Most common errors in valuation. IESE Business School - University of Navarra.

30. Ferrara, E. e. (2016). The rise of social bots. Communications of the ACM, 96-104.

750

31. Fink, L. (2020). Larry Fink's 2020 Letter to CEOs - A Fundamental Reshaping of Finance.

32. Fox, J. (2017). Applied regression analysis, linear models, and related methods. Sage Publications, Inc.

33. Ghassim, B., \& Bogers, M. (2019). Linking stakeholder engagement to profitability through 754

34. Global Sustainable Investment Alliance. (2018). Global Sustainable Investment Review 2018.

35. Gonzalez-Bailon, S., Wang, N., Rivero, A., Borge-Holthoefer, J., \& Moreno, Y. (2012).

36. Gyönyörová, L., Stachoň, M., \& Stašek, D. (2021). ESG ratings: relevant information or misleading clue? Evidence from the S\&P Global 1200. Journal of Sustainable Finance \& Investment. 
37. Hanck, C., Arnold, M., Gerber, A., \& Schmelzer, M. (2021). Introduction to Econometrics with R. Department of Business Administration and Economics University of Duisburg-Essen.

38. Hashimzade, N., \& Thornton, M. N. (2013). Handbook of Research Methods and Applications in Empirical Macroeconomics. Edward Elgar Publishing.

39. Hayes, A. F., \& Cai, L. (2007). Using heteroskedasticity-consistent standard error estimators in OLS regression: An introduction and software implementation. Behavioral Research Methods, pp. 709-722.

40. He, W., Guo, L., Shen, J., \& Akula, V. (2016). Social Media-Based Forecasting: A Case Study of Tweets and Stock Prices in the Financial Services Industry. Journal of Organizational and End User Computing.

41. Hite, K. A., \& Seitz, J. L. (2021). Global issues: an introduction. John Wiley \& Sons.

42. Hossain, M. (2021). Frugal innovation and sustainable business models. Technology in Soceity, 64, 101-508.

43. Iglesias, C. A., \& Moreno, A. (2019). Sentiment Analysis for Social Media. MDPI.

44. Ilyas, I., \& Osiyevskyy, O. (2021). Exploring the impact of sustainable value proposition on firm performance. European Management Journal.

45. Inoue, A. K. (2013). Inference on impulse response functions in structural VAR models. Journal of Econometrics, 1-13.

46. Institut für Demoskopie Allensbach. (2013). Allensbacher Markt-und Werbeträgeranalyse (AWA).

47. Investment Insights Center BNP Paribas. (2019). Is there a cost to sustainability.

48. Janis, L. I. (1972). Victims of groupthink: A psychological study of foreign-policy.

49. Johansen, S. (1991). Estimation and Hypothesis Testing of Cointegration Vectors in Gaussian Vector Autoregressive Models. In Econometria (pp. 1551-1580). The Econometric Soceity. 
50. Kahre, K., Darekar, O., Gupta, P., \& Attar, V. Z. (2017). Short term stock price prediction using deep learning. 2017 2nd IEEE International Conference on Recent Trends in Electronics, Information \& Communication Technology (RTEICT).

51. Kamalduin, M. F., Xavier, J. A., \& Amin, M. (2021). Social Entrepreneurship and Sustainability: A Conceptual Framework. Journal of Social Entrepreneurship, 1-24.

52. Kenne, D., \& Heede, R. (2021). Energy Research \& Social Science. Elsevier Ltd.

53. Kesterton, L. (2019). Navigating with ESG ratings: What you need to know.

54. Kim, S., Terlaak, A., \& Potoski, M. (2021). Corporate sustainability and financial performance: Collective reputation as moderator of the relationship between environmental performance and firm market value. Business Strategy and the Environment, 1689-1701.

55. Kolloch, M., \& Golker, O. (2016). Staatliche Regulierung und Digitalisierung als Antezedenzien für Innovationen in der Energiewirtschaft am Beispiel von REMIT. Zeitschrift für Energiewirtschaft, 41-54.

56. La Torre, M., Mango, F., Cafaro, A., \& Leo, S. (2020). Does the ESG Index Affect Stock Return? Evidence from the Eurostoxx50. Sustainability(12(16)).

57. Laitenberger, O., \& Dreyer, H. (1998). Evaluating the usefulness and the ease of use of a Web-based inspection data collection tool. IEEE, 122-132.

58. Lau, A. Y., Gabarron, E., Fernandez-Luque, L., \& Armayones, M. (2012). Social Media in Health — What are the Safety Concerns for Health Consumers? Health Information Management Journal, pp. 30-35.

59. Li, X., Xie, H., Chen, L., Wang, J., \& Deng, X. (2014). News impact on stock price return via sentiment analysis. Knowledge Based Systems, pp. 14-23.

60. Liu, B., \& Zhang, L. (2012). Analysis, A Survey of Opinion Mining and Sentiment. Mining Text Data, 415-463. 
61. Mao, Y., Wang, B., Wei, W., \& Liu, B. (2011). Correlating S\&P 500 Stocks with Twitter Data.

62. Mayo, H. (2020). Investments: an introduction. Cengage Learning.

63. McKinsey \& Company. (2014). Sustainability's strategic worth.

64. McKinsey \& Company. (2019). McKinsey-Studie: Nachhaltigkeitist das neue Must-have. McKinsey \& Company.

65. McKinsey \& Company. (2020). The ESG premium: New perspectives on value and performance.

66. Moa, H., Counts, S., \& Bollen, J. (2011). Predicting Financial Markets: Comparing Survey, News, Twitter and Search Engine Data.

67. Moonsoo, Viswanathan, White, \& Zychowicz. (2021). Sustainability efforts, index recognition, and stock performance. Journal of Asset Management, pp. 120-132.

68. Morse, D. (1984). An Econometric Analysis of the Choice of Daily Versus Monthly Returns in Tests of Information Content. Journal of Accounting Research, pp. 605-623.

69. Mushtaq, R. (2011). Augmented Dickey Fuller Test.

70. Nguyen, T. H., \& Shirai, K. (2015). Topic Modeling based Sentiment Analysis on Social Media for Stock Market Prediction. Proceedings of the 53rd Annual Meeting of the Association for Computational Linguistics and the 7th International Joint Conference on Natural Language Processing, pp. 1354-1364.

71. Nguyen, T. H., Elmagrhi, M. H., Ntim, C. G., \& Wu, Y. (2021). Environmental performance, sustainability, governance and financial performance: Evidence from heavily polluting industries in China. Business Strategy and the Environment.

72. Pancer, E., \& Poole, M. (2016). The popularity and virality of political social media: hashtags, mentions, and links predict likes and retweets of 2016 US presidential nominees' tweets. Social Influence, 4, pp. 259-270. 
73. Partidario, M. R. (2021). Strategic thinking for sustainability (ST4S) in strategic environmental assessment. Edward Elgar Publishing.

74. Pawar, A. B., Jawale, M. A., \& Kyatanavar, D. N. (2016). Fundamentals of Sentiment Analysis: Concepts and Methodology. In Sentiment Analysis and Ontology Engineering (pp. 25-48). Springer.

75. Perrin, A. (2015). Social Media Usage: 2000 - 2015. Pew Research Center.

76. Pfaff, B. (2008). Analysis of Integrated and Cointegrated Time Series with R (2nd ed.). Journal of Statistical Software, 54-95.

77. Plass, G. N. (1956). The Carbon Dioxide Theory of Climatic Change.

78. Porshnev, A., Redkin, I., \& Shevchenko, A. (2013). Machine learning in prediction of stock market indecators based on historical data and data from twitter sentiment anaylsis. 2013 IEEE 13th International Conference on Data Mining Workshops.

79. Prabowo, R., \& Summers, L. H. (1984). The persistence of volatility and stock market. National Bureau of Economic Research.

80. PricewaterhouseCoopers. (2021). eReadiness 2021 Survey Report. PricewaterhouseCoopers.

81. Rao, T., \& Srivastava, S. (2014). Twitter Sentiment Analysis: How to Hedge Your Bets in the Stock Markets. In State of the Art Applications of Social Network Analysis (pp. 227-247). Springer.

82. Rapaport, E. (2020). Sustainable ETFs outpace the rest during market sell-off.

83. Rehman Khan, S. A., \& Yu, Z. (2021). Assessing the eco-environmental performance: an PLS-SEM approach with practice-based view. International Journal of Logistics Research and Applications, 303-321.

84. Robinson, L. (2021). Canaries in the climate coal mine: Climate change and COVID-19 as meta-crisis. First Monday. 
85. Rode, J. (2018). Stuttgart sperrt alte Diesel aus - aber nicht den LEH. Lebensmittel Zeitung, 33.

86. Roßbach, P. (2001). Behavioral Finance - Eine Alternative zur vorherrschenden Kapitalmarkttheorie.

87. Sahut, J.-M., \& Pasquini-Descomps, H. (2015). ESG Impact on Market Performance of Firms: International Evidence. Management Interntional, pp. 40-63.

88. Scott Morton, F. M., \& Dinielli, D. C. (2020). Roadmap for an Antitrust Case Against Facebook. Omidyar Network.

89. Selwyn, N., \& Stirling, E. (2015). Social media and education ... now the dust has settled. Learning, Media and Technology, pp. 1-5.

90. Shapiro, H., Sudhof, M., \& Wilson, D. (2020). Measuring news sentiment. Federal Reserve Bank of San Francisco.

91. Tagesschau. (2021). Aufräumarbeiten und steigende Opferzahlen.

92. Tanaltay, A., Langroudi, S. A., Akhavan-Tabatabaei, R., \& Kasap, N. (2021). Can Social Media Predict Soccer Clubs' Stock Prices? The Case of Turkish Teams and Twitter. Sage Open, pp. 1-20.

93. Tillman, J. A. (1975). The Power of the Durbin-Watson Test. In Economertrica (pp. 9591975). The Econometric Society.

94. Toda, H. Y., \& Phillips, P. C. (1994). Vector autoregression and causality: a theoretical overview and simulation study. Econometric Reviews, 259-285.

95. Twitter Usage Statistics. (2021, November 14). Retrieved November 14, 2021, from https://www.internetlivestats.com/twitter-statistics/

96. van der Gaas, W., \& Begg, K. (2012). Challenge 1: Placing Climate Actions in a Wider Sustainable Development Context. Springer. 
97. Velenturf, A. P., \& Purnell, P. (2021). Principles for a sustainable circular economy. Sustainable Production and Consumption, 27, 1347-1457.

98. Wajid, K., Ara, N., Madiha, K., Waseem Khan Qaiser, K., \& Shabeer, A. (2013). The Impact of Capital Structure and Financial Performance on Stock Returns "A Case of Pakistan Textile Industry'. Middle-East Journal of Scientific Research, 289-295.

99. Walzenberg, J., Lonca, G., Hanes, R. J., Eberle, A. L., \& Carpenter, A. (2021). Do We Need a New Sustainability Assessment Method for the Circular Economy? A Critical Literature Review. Frontiers in Sustainability, 12.

100. Wang, C.-J., Tsai, M.-F., Liu, T., \& Chang, C.-T. (2013). Financial Sentiment Analysis for Risk Prediction. International Joint Conference on Natural Language Processing, pp. 802808.

101. Warren, B. (2019). Why investors are putting sustainability at the top of the agenda. Ernst \& Young.

102. Yoon, B., Lee, J. H., \& Byun, R. (2018). Does ESG Performance Enhance Firm Value? Evidence from Korea. Sustainability(10 (10)).

103. Zhang, W., \& Skiena, S. (2010). Trading Strategies to Exploit Blog and News Sentiment. Fourth Int. Conf. on Weblogs and Social Media.

104. Zhang, X., Fuehres, H., \& Gloor, A. P. (2011). Predicting Stock Market Indicators Through Twitter "I hope it is not as bad as I fear". Procedia - Social and Behavioral Sciences, pp. 5562.

105. Zheludev, I., Smith, R., \& Aste, T. (2014). When Can Social Media Lead Financial Markets? Sientific Reports.

106. Zivot, E., \& Wang, J. (2002). Vector Autoregressive Models for Multivariate Time Series. Modeling Financial Time Series with S-Plus, 369-413. 